\title{
Oceanographic changes in the North Pacific Ocean over the past century recorded in deep-water gorgonian corals
}

\author{
Branwen Williams ${ }^{1,4, *}$, Mike Risk $^{2}$, Robert Stone ${ }^{3}$, Daniel Sinclair ${ }^{1}$, Bassam Ghaleb ${ }^{1}$ \\ ${ }^{1}$ GEOTOP, Université du Québec à Montréal (UQAM)-McGill, CP 8888, Succursale Centre-Ville, Montréal, Québec H3C 3P8, \\ Canada \\ ${ }^{2}$ McMaster University, 1280 Main Street West, Hamilton, Ontario L8S 4L8, Canada \\ ${ }^{3}$ NMFS Auke Bay Laboratory, 11305 Glacier Highway, Juneau, Alaska 99801, USA \\ ${ }^{4}$ Present address: School of Earth Sciences, Ohio State University, Columbus, Ohio 43210, USA
}

\begin{abstract}
Deep-water gorgonian corals are long-lived and abundant in the North Pacific Ocean. Gorgonians have annually-resolved skeletal organic bands, making them proxies of environmental changes. Specimens of Primnoa sp. were collected from the Gulf of Alaska in 2001, 2003, and 2004. Organic band counts and ${ }^{210} \mathrm{~Pb}$ dating were combined to produce a growth chronology for 2 specimens. Organic skeletal growth bands were dissected and analysed for ${ }^{13} \mathrm{C}$ and ${ }^{15} \mathrm{~N}$ to investigate long-term changes in production and cycling of organic matter in surface waters. Three specimens were analyzed: PAL, P26 and P88. Specimen PAL, with a record spanning 125 yr, exhibits a statistically significant systematic depletion of ${ }^{13} \mathrm{C}$ and ${ }^{15} \mathrm{~N}$ over time. The magnitude of the depletion trend in the carbon record over the past $50 \mathrm{yr}$ is equivalent to the ${ }^{13} \mathrm{C}$ depletion of ocean surface dissolved inorganic carbon from the input of anthropogenic carbon into the atmosphere (the Suess effect). The depletion in ${ }^{15} \mathrm{~N}$ may reflect changes in plankton composition at the bottom of the food web.
\end{abstract}

KEY WORDS: Deep-water corals $\cdot$ North Pacific $\cdot$ Stable isotopes $\cdot$ Biogeochemistry

\section{INTRODUCTION}

Long-term trends in oceanic productivity and nutrient dynamics are poorly known, inviting efforts to recover such information from proxy sources. Skeletal records from long-lived, deep-water gorgonian corals appear particularly promising. Gorgonians are abundant in the North Pacific Ocean (Heifetz 2002), can live for hundreds of years (Risk et al. 2002), and have skeletons that are formed from repeated couplets of calcite (calcium carbonate) and gorgonin (organic) material (Heikoop et al. 2002, Sherwood 2002). The annual periodicity of the calcite-gorgonin skeletal couplets was inferred from ${ }^{210} \mathrm{~Pb}$ dating by Andrews et al. (2002) and later validated using bomb- ${ }^{14} \mathrm{C}$ dating by Sherwood et al. (2005a), allowing the growth of the skele- ton to be tracked and accurately dated with annual resolution.

Deep-water gorgonians record productivity, nutrient signals, and the Suess effect (see below, this section) in their skeletons (Heikoop et al. 2002, Sherwood et al. 2005b). Gorgonians feed on the seston, particularly detrital and living particulate organic matter (POM) (Orejas et al. 2003). Therefore, sinking POM from surface waters is probably a major supply of carbon and nitrogen to the deep-water gorgonian skeleton, although re-suspended material from benthic biological processes may contribute. The skeleton is isotopically enriched compared to the polyps and POM recently exported from surface waters (Heikoop et al. 2002, Sherwood et al. 2005b). Sherwood et al. (2005b) found a strong correlation between apparent oxygen 
utilization in surface waters (a measure of surface productivity) and $\delta^{13} \mathrm{C}$ and $\delta^{15} \mathrm{~N}$ of the gorgonian organic skeleton, demonstrating that gorgonians record surface water processes.

Externally derived terrestrial organic matter and organic carbon produced in situ by phytoplankton utilizing dissolved inorganic carbon (DIC) are the 2 main sources of carbon for POM. Marine DIC largely originates from the dissolution of atmospheric $\mathrm{CO}_{2}$ into surface waters. Biological fixation of this DIC preferentially extracts ${ }^{12} \mathrm{C}$. This results in fractionation, the magnitude of which depends on growth rate, dissolved $\mathrm{CO}_{2}$ concentrations, and plankton physiology (Hofmann et al. 2000, Laws et al. 2002). In addition, the $\delta^{13} \mathrm{C}$ signature of this carbon has been decreasing (known as the Suess effect) as a result of the penetration of anthropogenic $\mathrm{CO}_{2}$ into surface waters (Quay et al. 1992). These processes result in organic matter characterized by average $\delta^{13} \mathrm{C}$ values of $-21 \%$ (Gearing et al. 1984). In comparison, terrestrial organic matter from $\mathrm{C} 3$ plants is characterized by lower $\delta^{13} \mathrm{C}$ values (approximately $-27 \%$ ).

Much of the variation in the $\delta^{15} \mathrm{~N}$ of POM results from fractionation processes that occur during primary production (i.e. preferential uptake of ${ }^{14} \mathrm{~N}$, Needoba et al. 2003), and the subsequent enrichment of ${ }^{15} \mathrm{~N}$ with each step in the food chain. The $\delta^{15} \mathrm{~N}$ of phytoplankton will also reflect nitrogen availability relative to biological supply (Altabet et al. 1991, Wu et al. 1997). In closed systems, bioavailable nitrogen (usually nitrate, Waser et al. 2000 ) is supplied seasonally and is subsequently rapidly consumed. As nitrate is consumed and ${ }^{14} \mathrm{~N}$ preferentially removed, the remaining nitrate pool, and consequently phytoplankton, becomes progressively ${ }^{15} \mathrm{~N}$-enriched. As a result, the $\delta^{15} \mathrm{~N}$ of POM will be a reflection of phytoplankton uptake versus physical supply of nitrate. Contrastingly, in open systems with an abundant supply of nitrate, phytoplankton will be consistently ${ }^{15} \mathrm{~N}$-depleted relative to the source of nitrate in the surface ocean (Altabet et al. 1991, Waser et al. 2000).

In the current study, we use the annually-banded gorgonian skeleton to construct its growth chronology and to analyse the relationship between surface processes and the skeletal $\mathrm{C}$ - and $\mathrm{N}$-isotopic composition with the aim of retrieving historical oceanographic and biogeochemical information for the North Pacific Ocean. We present $\mathrm{C}$ and $\mathrm{N}$ isotope data from the organic skeletons of 3 specimens of Primnoa sp. collected live in 2001, 2003, and 2004 from different locations: the Aleutian Islands, northern Gulf of Alaska, and coastal southeastern Gulf of Alaska. Changes in the isotopic composition of the skeleton along a growth axis were measured and then interpreted as changes in local environmental conditions that influence the food source of the coral.

\section{MATERIALS AND METHODS}

Sample collection. Three Primnoa sp. specimens were collected opportunistically from the Gulf of Alaska (Fig. 1) during annual research surveys by NOAA Fisheries, Alaska Fisheries Science Center. Coral specimen collection was not the primary purpose of the research surveys and collections were therefore limited to 1 specimen per location. More detailed taxonomic identification of the specimens was not possible at the time since the taxonomy of the genus Primnoa has only recently been evaluated in detail. Specimen PAL was collected in 2003 at Portlock Bank $\left(58.38^{\circ} \mathrm{N}\right.$, $148.77^{\circ} \mathrm{W}$ ) from a water depth of $123 \mathrm{~m}$. Specimen P26 was collected in 2004 from the Aleutian Islands $\left(52.96^{\circ} \mathrm{N}, 169.43^{\circ} \mathrm{W}\right)$ from a water depth of $429 \mathrm{~m}$. Specimen P88 was collected in 2001 in Frederick Sound, Southeast Alaska $\left(57.23^{\circ} \mathrm{N}, 134.07^{\circ} \mathrm{W}\right)$ from a water depth of $110 \mathrm{~m}$. All specimens were collected live. The lower 10 to $30 \mathrm{~cm}$ of each specimen, including the colony base, was removed from the colony, air dried while at sea, and shipped to the laboratory for analysis. Soft tissue was removed with forceps after drying and prior to shipment.

Dating. Using a rock saw, 2 cross-sections (each $1 \mathrm{~cm}$ thick) were cut from the base of each specimen. The first section from each specimen was cleaned ultrasonically with Milli-Q water 3 times for 10 min each. The water was refreshed each time. The sections were re-cut to a uniform $0.5 \mathrm{~cm}$ width and polished. Photographs of each polished-section were taken with a digital camera using a macro lens. A radial segment from each photograph was magnified $400 \%$ and printed in colour. Using these photographs, band count - in which 1 band is composed of a couplet of 1 gorgonin and 1 calcite band-were carried out independently by 3 individuals to assess uncertainty in the age assignment.

Band counts were compared to dating based on skeletal ${ }^{210} \mathrm{~Pb}$ decay through ${ }^{210} \mathrm{Po}$ daughter measurements (Druffel et al. 1990). The thick cross-sections were sub-sampled $(>0.5 \mathrm{~g})$ using a wafering blade attached to a Dremel Multipro Drill for ${ }^{210} \mathrm{~Pb}$ analysis. Three sub-samples were taken from specimens P26 and P88, and 4 sub-samples were taken from PAL. Each sub-sample was from a different chronological time period and represented an average of about 20 bands. Sub-samples were cleaned 3 times ultrasonically with Milli-Q water for 10 min to ensure removal of all particles not incorporated into the skeleton and dried overnight at $40^{\circ} \mathrm{C}$. After cleaning, sub-samples were handled with clean forceps at all times to prevent contamination. ${ }^{209}$ Po spike ( 3 disintegrations per minute, dpm) was added to each sub-sample, followed by concentrated $\mathrm{HNO}_{3}$ (to dissolve the calcite skeleton) and concentrated $\mathrm{H}_{2} \mathrm{O}_{2}$ (to dissolve the organic skeleton). 


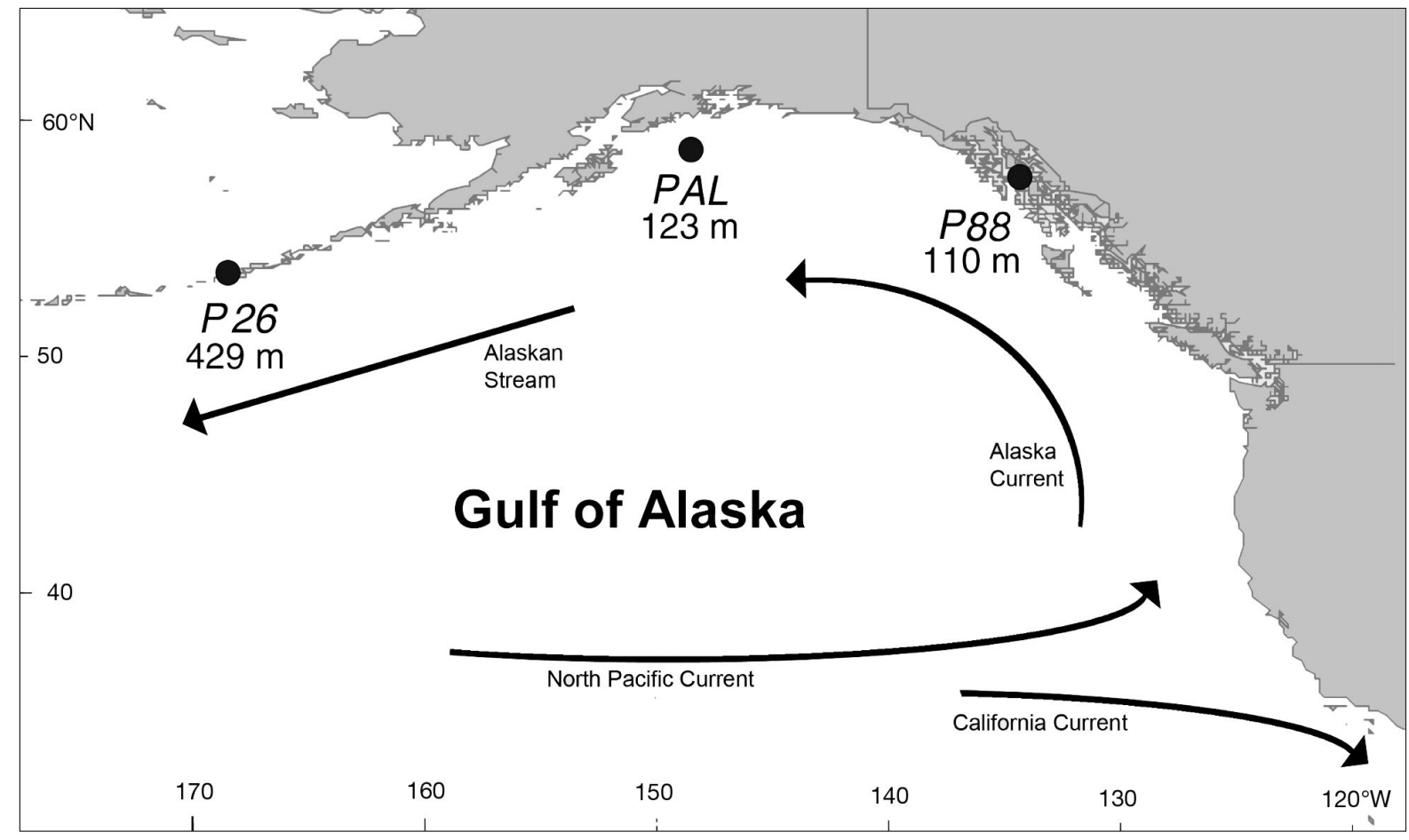

Fig. 1. Location of Primnoa sp. collection sites in the North Pacific Ocean

The ${ }^{209} \mathrm{Po}$ spike was used to determine ${ }^{210} \mathrm{Po}$, the activity of which should correspond to ${ }^{210} \mathrm{~Pb}$ because they are in secular equilibrium. Dissolutions were carried out on a low temperature hot plate until the samples were completely dissolved and dried. The dried residue was then re-dissolved in a concentrated mixture of $1 / 3$ $\mathrm{HNO}_{3}$ and $2 / 3 \mathrm{HCl}$ on the hot plate until completely dissolved and dried. The dried residue was dissolved a final time in $0.5 \mathrm{~N} \mathrm{HCl} .{ }^{210} \mathrm{Po}$ was plated onto silver discs from the final solution at approximately $80^{\circ} \mathrm{C}$ for several hours. The ${ }^{210} \mathrm{Po}$ activity was counted in an Alpha Counter EGG-ORTIC 476 in the Radioisotope Geochemistry Laboratory at GEOTOP-UQAM-McGill.

Specimen age was determined by plotting sub-sample ${ }^{210} \mathrm{~Pb}_{\text {ex }}$ (excess [or supported] fraction of ${ }^{210} \mathrm{~Pb}$ ) activity against the distance from the outside edge of the section $(t=0)$ to the average width of each sub-sample. The log transformed ${ }^{210} \mathrm{~Pb}$ activity was plotted against radial distance such that the exponential of the $y$-intercept represents initial activity $\left(A_{0}\right)$. The law of radioactive decay can be used to describe the decay of ${ }^{210} \mathrm{~Pb}$ with time:

$$
A_{\mathrm{ex}}=A_{0} \mathrm{e}^{-\lambda t}
$$

where $A_{\text {ex }}$ is the activity measured at time $(t), A_{0}$ is the initial activity at time 0 , and $\lambda$ is the natural $\log$ of 2 divided by the half-life of ${ }^{210} \mathrm{~Pb}(22.3 \mathrm{yr})(\lambda=0.0311)$. The calculated initial activity, ${ }^{210} \mathrm{~Pb}_{\mathrm{ex}}$, and lambda can be substituted into the equation to determine the unknown time.
Band separation and isotopic analysis. For each specimen, a wedge was cut from the second thick section with a Dremel Multipro drill. For specimens PAL and P88, replicate wedges (PAL-1, PAL-2 and P88-1, P88-2, respectively) were cut from the opposite sides of the thick section. The wedges were placed for a week in sufficient $5 \% \mathrm{HCl}$ to cover the sample. The acid was refreshed each time the $\mathrm{pH}$ approached neutral. The acid dissolved the calcite bands, allowing separation of the remaining organic bands. These bands were peeled from the thick section, moving from outside (most recent) to inside (oldest). The location of each band was recorded on a magnified photograph of the polished sections before its removal. After dissection each band was left in $5 \% \mathrm{HCl}$ for a further $3 \mathrm{~d}$ to ensure all calcite had been dissolved. Each band was then rinsed in deionised water 3 times and dried at low temperature overnight. Using this technique, 124 bands were separated from specimen PAL, 72 from specimen P88, and 60 from specimen P26.

Each of the organic bands from specimen PAL-1 were sub-sampled ( 0.7 to $0.8 \mathrm{mg}$ ), while approximately 20 bands were sub-sampled from each of the other specimens due to time and financial constraints. Subsamples were analyzed for $\delta^{13} \mathrm{C}$ and $\delta^{15} \mathrm{~N}$ on a $\mathrm{GV}$ Instruments isoprime mass spectrometer connected in continuous-flow mode with a Carlo Erba NA 1500 elemental analyzer. Analyses were made at GEOTOPUQAM-McGill. Isotopic ratios are reported in the stan- 
dard delta notation versus VPDB and air for carbon and nitrogen, respectively. Accuracy and precision were measured using internal laboratory standards as well as the international standards USGS-25 and IAEA C6 sucrose. Isotopic homogeneity of gorgonian bands was tested by measuring 10 random sub-samples from 1 band of specimen PAL-1.

\section{RESULTS}

Specimen PAL displayed clear banding (Fig. 2) and 3 band counts from different people produced an age of $124 \pm 3$ yr from the outer layer to the inner sub-sampled layer. This was validated by ${ }^{210} \mathrm{~Pb}_{\text {ex }}$ data (Table 1). In contrast, specimens P26 and P88 did not display clear, consistent annual banding in the cross-sections examined. P26 contained sections of skeleton deficient in calcite, thus the skeleton was nearly solid dark brown making it difficult to distinguish and count bands. P88 had sufficient amounts of calcite and gorgonin in the skeleton but they were not formed in banded couplets throughout the entire cross-section. The inside section of the skeleton displayed clear annual banding while the outer region did not (Fig. 3), suggesting a shift in the dominant factors influencing the skeletal formation. The unclear annual banding in magnified photographs of specimens P26 and P88 made it impossible to produce an accurate band count.

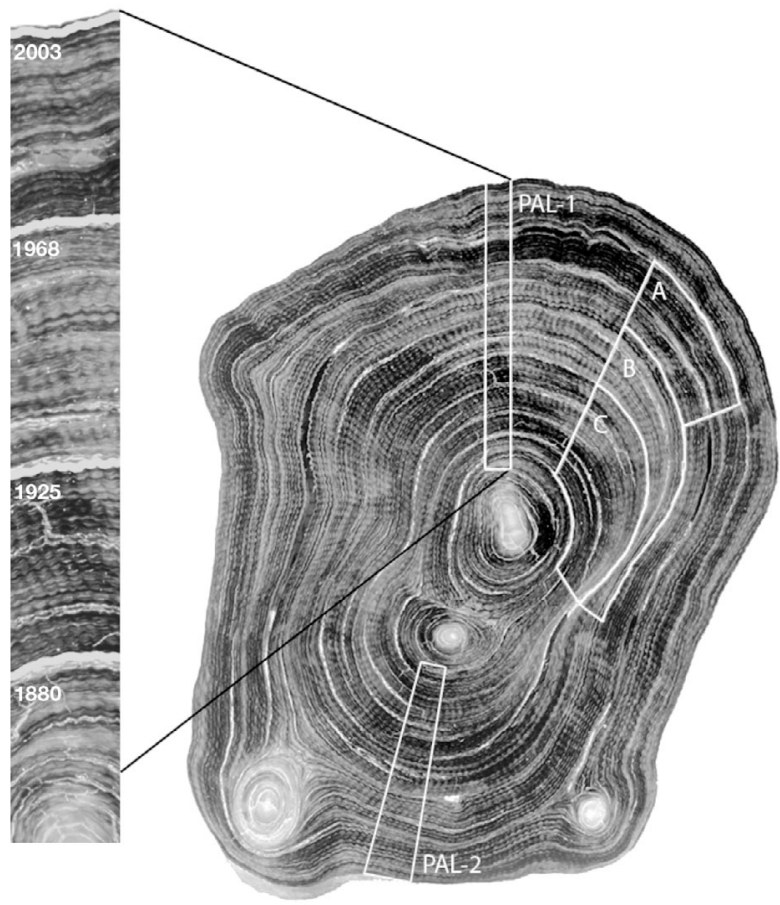

Fig. 2. Primnoa sp. Photograph of polished thick section of specimen PAL. Inset shows annual banding with the ages of 4 bands given. A-C: sub-samples (see Table 1)
Measured ${ }^{210} \mathrm{~Pb}$ activity and radial distance (from the center of each sub-sample to the outside of the crosssection) of each subsample are presented in Table 1. According to ${ }^{210} \mathrm{~Pb}$ dating, specimen PAL is $195 \mathrm{yr}$ old (we were only able to dissect bands going back $125 \mathrm{yr}$ ) and specimen P26 is ca. 53 yr old. The ${ }^{210} \mathrm{~Pb}$ results for specimen P88 was inconclusive due to the very low measured ${ }^{210} \mathrm{~Pb}$ activity.

Band dissection for specimen P26 was performed easily, suggesting that annual couplets were present; however, the poor quality of the polished section and dark colour of the material made them difficult to see in photographs. Sixty bands were dissected under light microscope for specimen P26. The discrepancy between ${ }^{210} \mathrm{~Pb}$ age estimate (53 yr) and dissected bands (60 yr) probably results from the imprecision in subsampling for ${ }^{210} \mathrm{~Pb}$ analysis. The dissected bands were assumed to be annual and used for sclerochronological applications.

For specimen P88, band dissection after calcite dissolution was difficult and although a tentative chronology has been adopted for specimen P88, we are not confident that the bands are annual. Only general, long-term trends can therefore be interpreted from the isotope data for this specimen.

Stable isotope results (Table 2) were plotted against years, as calculated from the band count for specimens PAL and P26, and against band count for specimen P88 (Figs. 4 \& 5). The outer (first) band was assumed to represent the year of collection since the specimens were

Table 1. Primnoa sp. Sub-sample age determined from ${ }^{210} \mathrm{~Pb}_{\mathrm{ex}}$ activity and extrapolated specimen age. Sub-samples were taken from the outside edge representing most recent growth (A) to the inside (C or D). Distance is measured along the radial growth axis from the outside of the thick section to the center of each sub-sample. The error is related to instrumental accuracy in measured ${ }^{210} \mathrm{~Pb}$ activity. Activity and age data are means (+/-SE). dpm: disintegrations per minute

\begin{tabular}{|lcccc|}
\hline Specimen & $\begin{array}{c}\text { Sub- } \\
\text { sample }\end{array}$ & $\begin{array}{c}\text { Distance } \\
(\mathrm{mm})\end{array}$ & $\begin{array}{c}\text { Activity } \\
\left(\mathrm{dpm} \mathrm{g}^{-1}\right)\end{array}$ & $\begin{array}{c}\text { Age } \\
(\mathrm{yr})\end{array}$ \\
\hline PAL & $\mathrm{A}$ & 0.1 & $2.25( \pm 0.08)$ & $11.6( \pm 1)$ \\
& $\mathrm{B}$ & 0.4 & $0.66( \pm 0.02)$ & $50.9( \pm 1)$ \\
& $\mathrm{C}$ & 0.7 & $0.26( \pm 0.02)$ & $80.8( \pm 1)$ \\
& $\mathrm{D}$ & 1.1 & $0.067( \pm 0.01)$ & $124.1( \pm 3)$ \\
& Center & 1.7 & & $194.5( \pm 5)$ \\
P88 & & & & \\
& $\mathrm{A}$ & 0.3 & $0.159( \pm 0.007)$ & $100.3( \pm 1)$ \\
& $\mathrm{B}$ & 0.7 & $0.084( \pm 0.006)$ & $120.9( \pm 1)$ \\
& $\mathrm{C}$ & 2.0 & $0.0006( \pm 0.0006)$ & 236.4 \\
P26 & Center & 2.3 & & $123.2( \pm 5)$ \\
& & & & \\
& $\mathrm{A}$ & 0.1 & $0.956( \pm 0.01)$ & $1.9( \pm 0.8)$ \\
& $\mathrm{B}$ & 0.5 & $0.554( \pm 0.01)$ & $19.4( \pm 1)$ \\
& $\mathrm{C}$ & 1.3 & $0.267( \pm 0.008)$ & $42.9( \pm 0.6)$ \\
& Center & 1.6 & $52.6( \pm 1)$ & \\
\hline
\end{tabular}




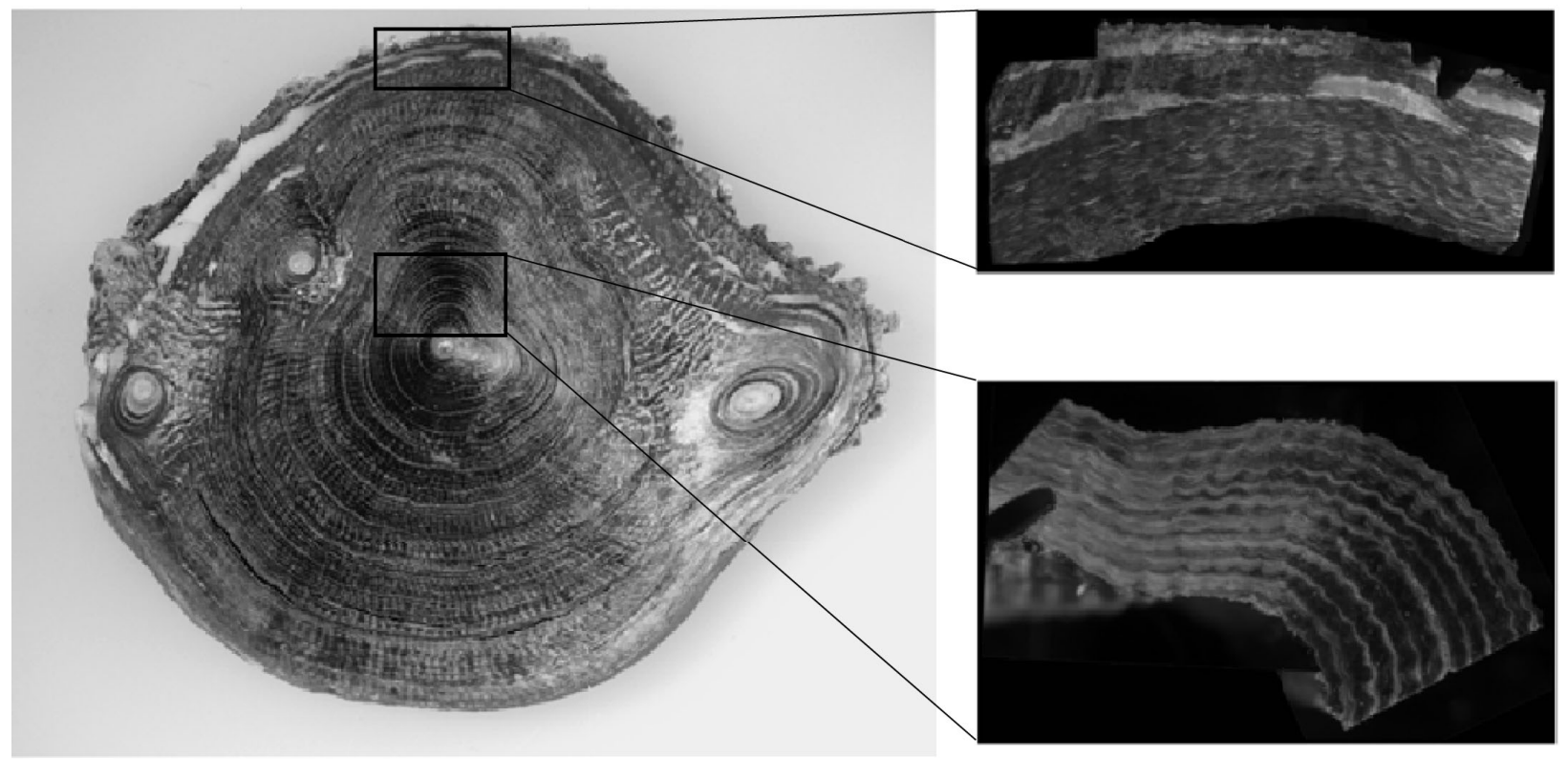

Fig. 3. Primnoa sp. Photograph of polished thick section of specimen P88. Top inset shows the unclear banding patterns in the massive calcite cortex, while bottom inset of the same specimen (viewed from reverse side) shows very clear annual banding in the horny axis

collected alive. The replicate tracks (1 and 2) were plotted independently on the same graph for specimens PAL and P88. A linear trend was fitted to each track (Table 3), the significance of which is strongly influenced by the number of points: the trends for the replicate track with the most sub-samples (PAL-1) are significant for both $\delta^{13} \mathrm{C}$ and $\delta^{15} \mathrm{~N}$ while the trend is not significant for either $\delta^{13} \mathrm{C}$ or $\delta^{15} \mathrm{~N}$ for the replicate tracks with the fewest points (P88-2 and PAL-2). The trend, its significance and number of points are listed in Table 3.

The instrumental precision for the isotopic data is $\pm 0.1 \%$ for $\delta^{13} \mathrm{C}$ and $\pm 0.2 \%$ for $\delta^{15} \mathrm{~N}$. The average reproducibility for sub-samples is $\pm 0.12 \%$ for $\delta^{13} \mathrm{C}$ and $\pm 0.22 \%$ for $\delta^{15} \mathrm{~N}$. $\delta^{13} \mathrm{C}$ is generally the highest in P88-1 (-17.8 to $-15.9 \%$, average $16.6 \%$ ), which is the shallowest and most coastal site, and lowest in P26 ( -20.2 to $-18.6 \%$, average $-19.8 \%)$, which is the deepest site. Specimen PAL-1 has an intermediate value $(-18.5$ to $-16.6 \%$, average $-17.5 \%$ ) (Table 2$)$, and a large perturbation in $\delta^{13} \mathrm{C}$ is present from 1935 to 1945 (Fig. 4). Specimens P88-2 (-16.9 to $-15.5 \%$, average $16.2 \%$ ) and PAL-2 ( -18.6 to $-16.7 \%$; average $-17.8 \%$ o) are similar to P88-1 and PAL-1, respectively. Specimens PAL-1 and P26 show significant depletion of ${ }^{13} \mathrm{C}$ values over time $(\mathrm{p}<0.0001$ and $\mathrm{p}=0.01$, respectively) (Table 3, Fig. 4). In contrast, specimen P88 exhibits little, if any, significant change $(p=0.92$ for P88-1, $\mathrm{p}=0.40$ for P88-2). In general, PAL-1 has the highest $\delta^{15} \mathrm{~N}$ value (10.9 to $13.2 \%$, average $12.2 \%$ ), P26 has the lowest value (8.7 to $9.9 \%$, aver- age $9.2 \%$ ), and P88-1 has an intermediate value (9.6 to $10.6 \%$, average $10.1 \%$ ). No consistent change in the nitrogen isotopic composition between specimens is present: PAL-1 shows a significant depletion of ${ }^{15} \mathrm{~N}$

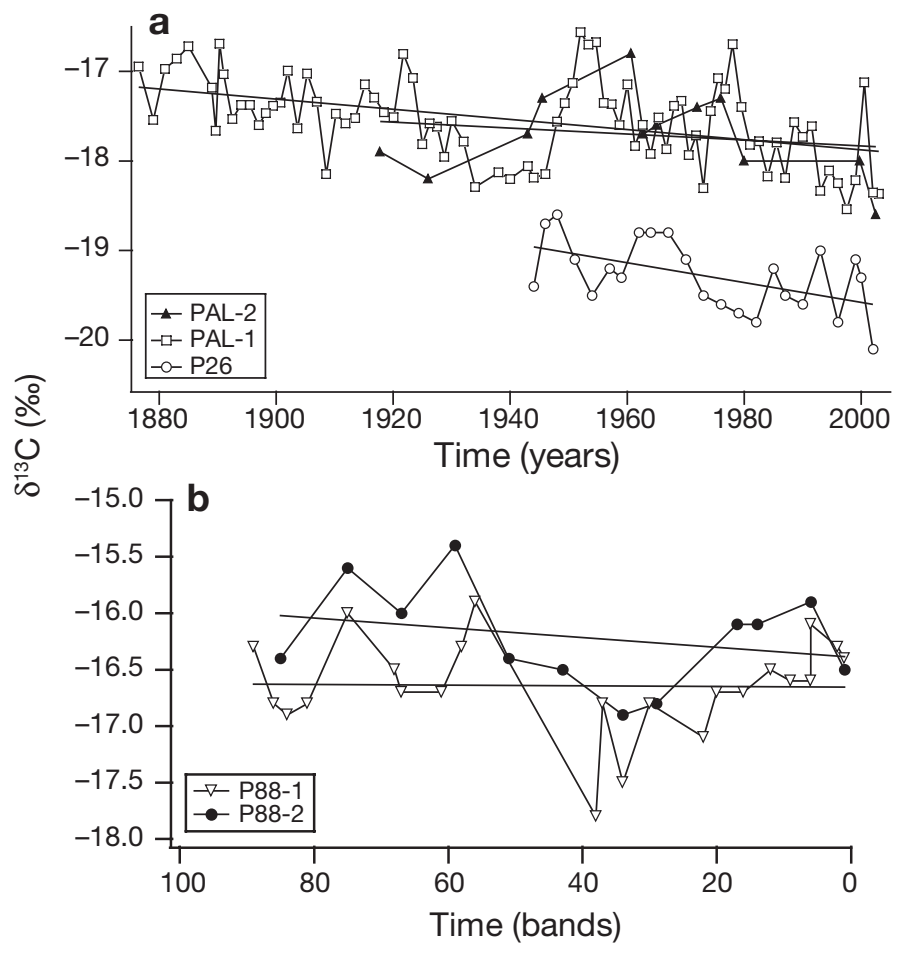

Fig. 4. Primnoa sp. $\delta^{13} \mathrm{C}$ ratios across a radial growth axis for (a) PAL-1, PAL-2 and P26, and (b) P88-1 and P88-2 versus time in years and bands, respectively 
Table 2. Primnoa sp. Carbon and nitrogen isotope results for all specimens

\begin{tabular}{|lccccc|}
\hline \multirow{2}{*}{ Specimen } & \multicolumn{2}{c}{$\delta^{13} \mathrm{C}(\%)$} & & & $\delta^{15} \mathrm{~N}(\%)$ \\
\cline { 2 - 3 } \cline { 5 - 6 } & Mean $( \pm \mathrm{SD})$ & Range & & Mean $( \pm \mathrm{SD})$ & Range \\
\hline PAL-1 & $-17.5( \pm 0.5)$ & 2.0 & & $12.2( \pm 0.4)$ & 2.2 \\
PAL-2 & $-17.8( \pm 0.5)$ & 1.9 & & $11.3( \pm 0.3)$ & 1.1 \\
P88-1 & $-16.6( \pm 0.4)$ & 1.8 & & $10.1( \pm 0.3)$ & 0.9 \\
P88-2 & $-16.2( \pm 0.5)$ & 1.5 & & $10.9( \pm 0.3)$ & 1.0 \\
P26 & $-19.3( \pm 0.4)$ & 1.7 & & $9.2( \pm 0.3)$ & 1.2 \\
\hline
\end{tabular}

( $\mathrm{p}<0.0001)$ and PAL-2 shows a non-significant depletion of ${ }^{15} \mathrm{~N}(\mathrm{p}=0.36)$, while P26 shows a significant enrichment $(p=0.02)$. P88-1 shows a significant depletion $(p=0.01)$ but no trend is present in P88-2 $(\mathrm{p}=0.81) . \delta^{15} \mathrm{~N}$ is less in PAL-2 (10.9 to $12.0 \%$, average $11.3 \%$ ) than in PAL-1, and higher in P88-2
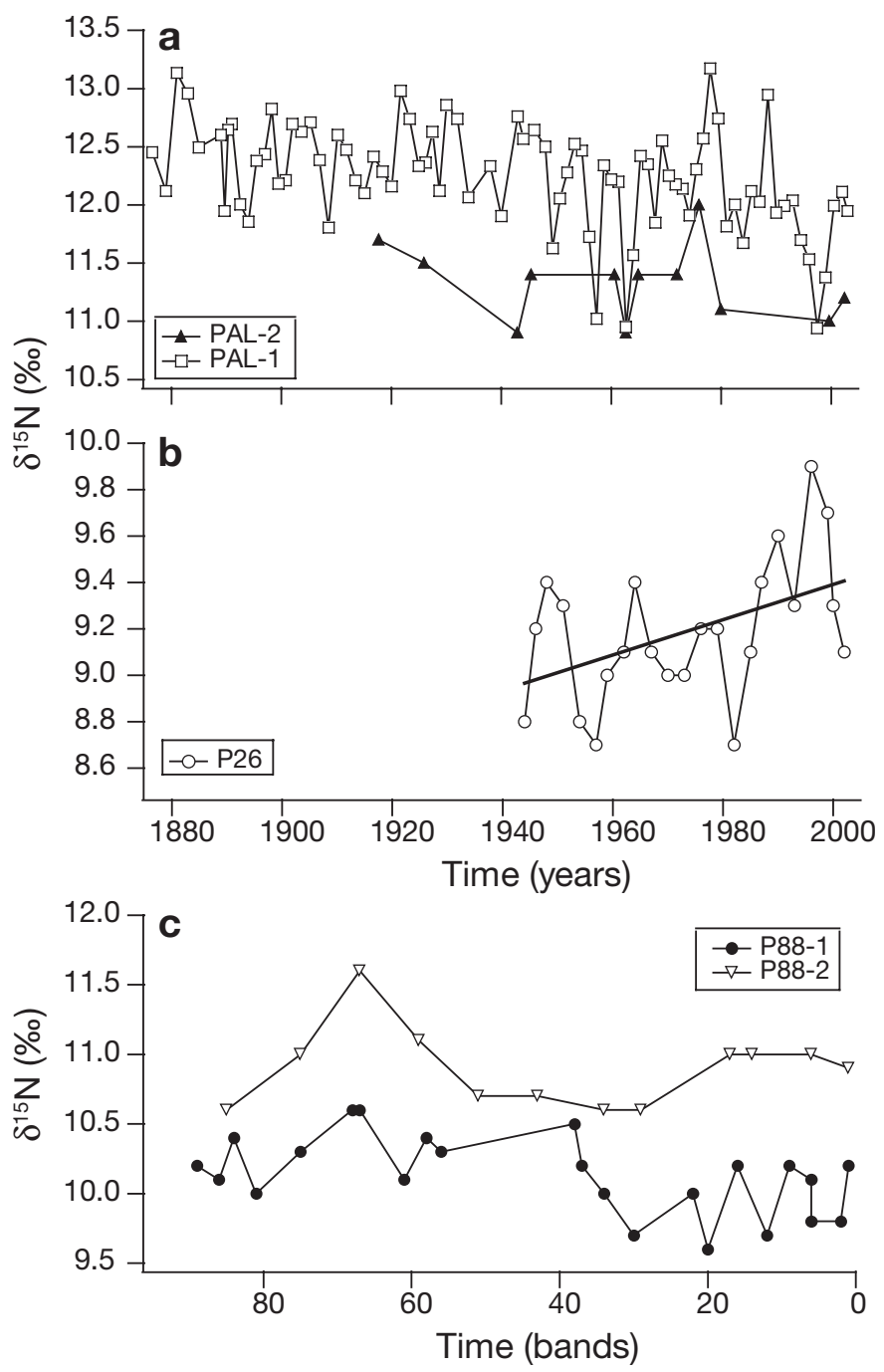

Fig. 5. Primnoa sp. $\delta^{15} \mathrm{~N}$ ratios across a radial growth axis for (a) PAL-1 and PAL-2, (b) P26 and (c) P88-1 and P88-2, all versus time in $(a, b)$ years and $(c)$ bands
(10.6 to $11.6 \%$; average $10.9 \%$ o) than in P88-1. A correlation between ${ }^{13} \mathrm{C}$ and ${ }^{15} \mathrm{~N}$ (Fig. 6) was evident for PAL-1 ( $p<0.001)$ and P88-2 ( $p=0.02)$; no correlation was present in PAL-2 ( $p=0.35)$, P88-1 (0.79), or P26 $(\mathrm{p}=0.76)$.

\section{DISCUSSION}

${ }^{210} \mathrm{~Pb}$ dating has been used to date deep-water gorgonians, although not always successfully (Druffel et al. 1990, Andrews et al. 2002). It is used in the current study with variable success (Table 1). Eq. (1) uses only ${ }^{210} \mathrm{~Pb}_{\text {ex }}$ activity in the skeleton. However, there are 2 sources of ${ }^{210} \mathrm{~Pb}$ present in the gorgonian skeleton: unsupported ${ }^{210} \mathrm{~Pb}\left({ }^{210} \mathrm{~Pb}_{\mathrm{ex}}\right)$ and ${ }^{210} \mathrm{~Pb}$ that is in secular equilibrium with parent isotopes of the uranium-238 decay series, notably ${ }^{226} \mathrm{Ra}$. To use the decay of ${ }^{210} \mathrm{~Pb}_{\mathrm{ex}}$ in the skeleton we must account for the supported fraction of ${ }^{210} \mathrm{~Pb} .{ }^{210} \mathrm{~Pb}_{\mathrm{ex}}$ was determined from the total measured ${ }^{210} \mathrm{~Pb}$ activity by subtracting the average ${ }^{226} \mathrm{Ra}$ activity for Primnoa sp. calculated from 15 subsamples previously analyzed for ${ }^{210} \mathrm{~Pb}$ and ${ }^{226} \mathrm{Ra}$ (Fig. 7). This dating method is based on the assumption that ${ }^{210} \mathrm{~Pb}$ is in secular equilibrium with ${ }^{226} \mathrm{Ra}$ (Druffel et al. 1990).

Age calculations based on Eq.(1) also assume that initial ${ }^{210} \mathrm{~Pb}_{\text {ex }}$ is constant in space and time. We could support this assumption by demonstrating that initial ${ }^{210} \mathrm{~Pb}_{\text {ex }}$ from several specimens collected from proximal locations is similar, and that initial ${ }^{210} \mathrm{~Pb}_{\mathrm{ex}}$ from specimens previously collected fits the decay curve. The success of this dating method in the current study varied among specimens, and may be influenced by growth. Although all 3 specimens were collected live, specimen P88 had started forming a calcified cortex (Fig. 3) before collection. This calcified cortex represents a third stage of growth and may have implications for the chemistry of the skeleton resulting in the poor age estimate from ${ }^{210} \mathrm{~Pb}$.

Differences in skeletal formation and growth banding in each specimen may reflect local oceanographic conditions. In samples of Primnoa resedaeformis from the northwestern Atlantic, formation of gorgonin-rich skeletal material corresponds to maximal surface productivity and intermediate current velocities, suggesting that gorgonin bands require more energy for growth than gorgonin-poor (calcite) skeleton (Sherwood 2002). In addition, the composition of the skeleton may be a response to current stress: gorgonin material increases skeletal flexibility while calcite increases stiffness (Grasshoff \& Zibrowius 1983 cited in Sherwood 2002). Food abundance coupled with the requirements for physical skeletal reinforcement may explain the variable amount of calcite and 
Table 3. Primnoa sp. Trends in isotopic abundances determined from fitted line equation. The straight line equation fitted to each track plotted in Figs. 4 \& 5 is shown. The significance of the trend has been determined by linear regression. N: number of bands analyzed for each track

\begin{tabular}{|lccccc|}
\hline Specimen & Isotope & Slope $\left(\times 10^{-3}\right)$ & $y$-intercept & Trend & Significance \\
\hline P88-1 & $\delta^{13} \mathrm{C}$ & $0.8 \pm 5.5$ & $-16.7 \pm 0.3$ & None & $\mathrm{p}=0.92$ \\
& $\delta^{15} \mathrm{~N}$ & $4.4 \pm 3.4$ & $9.9 \pm 0.2$ & Depletion & $\mathrm{p}=0.01$ \\
P88-2 & $\delta^{13} \mathrm{C}$ & $6.4 \pm 8.0$ & $-16.5 \pm 0.4$ & Depletion & $\mathrm{p}=0.40$ \\
& $\delta^{15} \mathrm{~N}$ & $1.7 \pm 5.4$ & $10.8 \pm 0.3$ & None & $\mathrm{p}=0.82$ \\
PAL-1 & $\delta^{13} \mathrm{C}$ & $5.6 \pm 2.5$ & $-17.9 \pm 0.2$ & Depletion & $\mathrm{p}<0.0001$ \\
& $\delta^{15} \mathrm{~N}$ & $5.1 \pm 2.4$ & $11.9 \pm 0.3$ & Depletion & $\mathrm{p}<0.0001$ \\
PAL-2 & $\delta^{13} \mathrm{C}$ & $2.4 \pm 7.7$ & $-17.9 \pm 0.4$ & None & $\mathrm{p}=0.57$ \\
P26 & $\delta^{15} \mathrm{~N}$ & $3.3 \pm 5.8$ & $11.2 \pm 0.3$ & Depletion & $\mathrm{p}=0.36$ \\
& $\delta^{13} \mathrm{C}$ & $9.3 \pm 5.4$ & $-19.7 \pm 0.3$ & Depletion & $\mathrm{p}=0.01$ \\
& $\delta^{15} \mathrm{~N}$ & $-3.9 \pm 4.2$ & $9.3 \pm 0.2$ & Enrichment & $\mathrm{p}=0.02$ \\
\hline
\end{tabular}

gorgonin in the different specimens discussed in the present study.

Specimen PAL, with the clearest banding, was collected close to Portlock Bank (Fig. 1), coinciding with the transition of the Alaska Current into the Alaskan Stream. This is predominately a downwelling region; however, in summer downwelling relaxes and nutrient-rich deeper waters (Royer 1975) inundate the surface waters, providing an abundance of nutrients and fostering high primary productivity (Stabeno et al. 2004). This strong seasonal nutrient input is likely responsible for the clear annual banding visible in specimen PAL.

Specimen P26 was collected from the south side of Umnak Island in the eastern Aleutian Islands, directly in the path of the Alaskan Stream. It was collected at $429 \mathrm{~m}$, substantially deeper than specimen PAL $(123 \mathrm{~m})$ and P88 $(110 \mathrm{~m})$, and below the mixed layer depth (approximately $140 \mathrm{~m}$ in winter, Sarkar et al. 2005). The surface waters are dominated year round by very small phytoplankters that occur at low and seasonally stable abundances (Booth 1988). Consequently, fluctuations in food that may trigger changes in band composition (i.e. gorgonin versus calcite) are less of a dominant factor, potentially explaining the diminished visibility of annual growth couplets.

Specimen P88, which has poorly defined banding in places, was collected from the inside waters of the southeastern Gulf of Alaska and is affected by coastal currents that are driven by terrestrial runoff of freshwater (Royer 1981). Although seasonal cycles in the temperature and salinity of the coastal waters are observed (Xiong \& Royer 1984), seasonal upwelling or nutrient pulses that can cause annual growth patterns may not be a strong environmental factor. This might explain the poorly defined banding of the specimen.

The reproducibility of $\delta^{13} \mathrm{C}$ and $\delta^{15} \mathrm{~N}$ determined from sub-samples of 1 band was only slightly higher than instrumental reproducibility. This suggests there is very little isotopic heterogeneity within individual gorgonian bands. $\delta^{13} \mathrm{C}$ results are also generally reproducible between 2 replicate tracks from 1 specimen (see P88-1 and P88-2, from bands 60 to 85, Fig. 4). However, larger offsets are observed for $\delta^{15} \mathrm{~N}$ : possibly the consequence of the hydrochloric acid treatment to dissolve the calcite portion of the skeleton. Heikoop et al. (2002) reported a constant, average enrichment

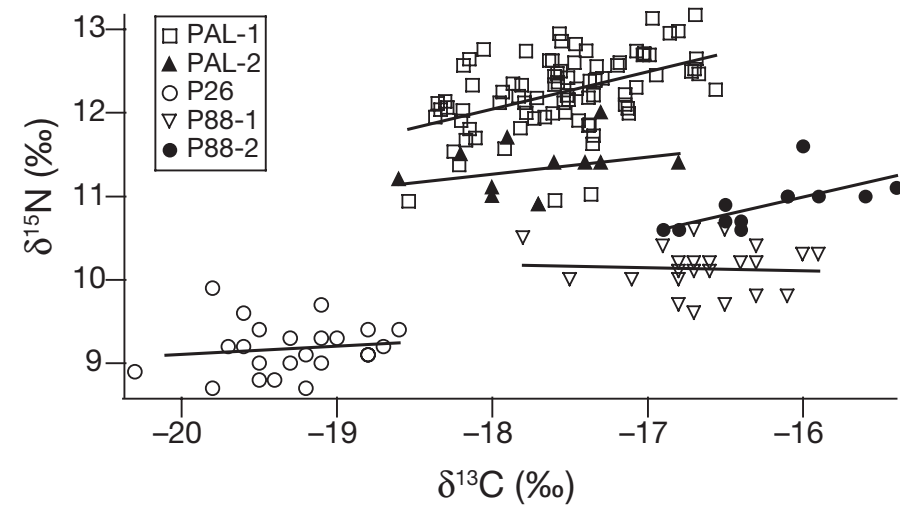

Fig. 6. Primnoa sp. $\delta^{15} \mathrm{~N}$ versus $\delta^{13} \mathrm{C}$ for all specimens

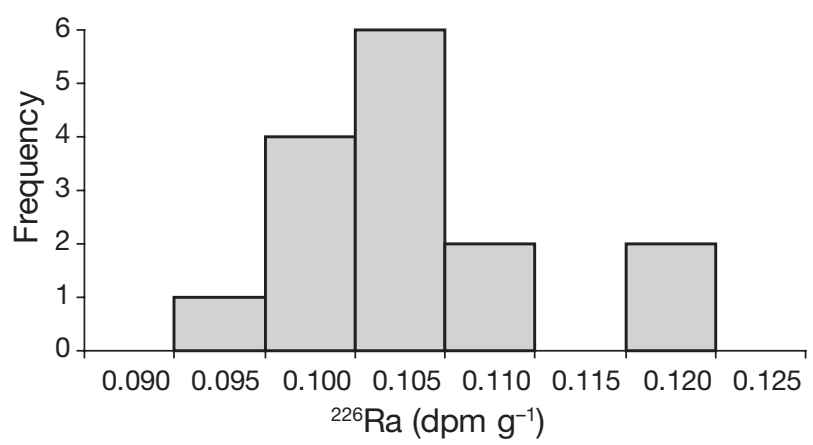

Fig. 7. Primnoa sp. ${ }^{226}$ Ra activities for 15 gorgonian sub-samples. Average ${ }^{226}$ Ra activity was 0.103 (data from B. Ghaleb \& O. Sherwood pers. comm.). dpm: disintegrations per minute 
in $\delta^{15} \mathrm{~N}$ values of $0.7 \%$ in sub-samples treated with varying strengths of acid $(0.1$ to $10 \% \mathrm{HCl})$ relative to untreated sub-samples. Sherwood et al. (2005b) found variability among specimens from 1 location to be excellent for carbon but poor for nitrogen isotopes. Correlation of time-series analysis was significant for $\delta^{13} \mathrm{C}(\mathrm{p}<0.0001)$ among 3 different specimens. The correlation was not significant for $\delta^{15} \mathrm{~N}_{\text {; }}$ however, all 3 specimens displayed the same long-term trends (Sherwood et al. 2005b).

The average $\delta^{13} \mathrm{C}$ isotopic composition differs significantly among specimens (Table 3). Productivity and plankton species composition display strong spatial variability in the North Pacific Ocean (Coyle \& Pinchuk 2005). For example, species composition was notably different in spring 2000 between the inner, middle, and outer shelf of the Gulf of Alaska (Coyle \& Pinchuk 2005). Species composition of plankton may be an important factor controlling $\delta^{13} \mathrm{C}$ values of the POM; therefore, the difference in $\delta^{13} \mathrm{C}$ could be explained in terms of specimens feeding on plankton of a different composition.

Values for $\delta^{13} \mathrm{C}$ decrease significantly as specimens PAL-1 and P26 increase in age. Specimens PAL-2 and P88-2 also show a depletion of ${ }^{13} \mathrm{C}$ (Fig. 4), although the trend is not significant at the $95 \%$ confidence interval, probably due to the low number of bands measured (Table 3 ). The depletion trends are probably caused by the infusion of anthropogenic $\mathrm{CO}_{2}$ into the ocean. The burning of fossil fuels has resulted in an increase in the concentration of carbon dioxide in the atmosphere and concomitant decrease in carbon-isotopic composition (Francey et al. 1999). The ocean is a net sink of atmospheric $\mathrm{CO}_{2}$ and takes up some of this light $\mathrm{CO}_{2}$. In the North Pacific Ocean, anthropogenic $\mathrm{CO}_{2}$ reaches a water depth of $1000 \mathrm{~m}$ (Feely et al. 2002), far deeper than all the specimens studied here. The sinking of surface POM in the water column transfers the atmospheric carbon signal to deeper waters, hence the gorgonian specimens were feeding on isotopically lighter carbon over time.

In the North Pacific Ocean, a decrease in $\delta^{13} \mathrm{C}$ values has been estimated to occur at $0.012 \% \mathrm{yr}^{-1}$ over a $5 \mathrm{yr}$ period from 1997 to 2002 (Tanaka et al. 2003). For the global surface oceans, it has been estimated at $0.018 \%$ $\mathrm{yr}^{-1}$ for the period of 1980 to 1995 (Gruber et al. 1999). We will use specimen PAL-1 to compare the results from the present study to those predicted by Tanaka et al. (2003) because it was the specimen with the highest number of analyzed bands. If we examine the data in the second half of the last century, a linear trend line from 1955 to 2003 shows a decrease in $\delta^{13} \mathrm{C}$ values of $0.7 \%$ over $48 \mathrm{yr}$, an average of $0.015 \% \mathrm{yr}^{-1}$. This corresponds well with the values estimated by Tanaka et al. (2003) and Gruber et al. (1999).
The ${ }^{13} \mathrm{C}$ depletion trend could also be enhanced by the increase in deforestation over the past half century. Land plants and other terrestrial organic matter have an average $\delta^{13} \mathrm{C}$ signature which is lower than that of marine matter, so increased input of terrestrial matter to the marine environment from deforestation could cause a decrease in the $\delta^{13} \mathrm{C}$ signature of POM. Tunnicliffe (2000) analyzed $\delta^{13} \mathrm{C}$ in varved sediments from an anoxic fjord in Saanich Inlet, British Columbia. The sediments exhibit a decrease in $\delta^{13} \mathrm{C}$ values of $1.2 \%$ from the 1860s to the late 1990s, which could be a result of increasing terrestrial input since the mid-19th century, corresponding to changes in land use including deforestation and sawmill operations in the watershed feeding into Saanich Inlet. In southern Alaska, substantial deforestation was initiated in the 1950s by the US Forest Service to aid the development of the pulp industry, and it has claimed between 30 and $40 \%$ of the coastal rainforest (Steiner 1998). The change in land use in southern Alaska could be responsible for the depletion of ${ }^{13} \mathrm{C}$ recorded in the gorgonian skeleton, particularly specimen P88, located from inside waters and strongly affected by terrestrial runoff.

In specimen PAL-1, a large perturbation is present between approximately 1935 and 1945 (i.e. $\delta^{13} \mathrm{C}$ decreases approximately $0.5 \%$; Fig. 4 ). This perturbation is also present in PAL-2, although not as strongly developed. Specimen P88 contains a depletion of ${ }^{13} \mathrm{C}$ in both replicate tracks, however, we are unable to assign a time for the depletion perturbation because the growth chronology is not firmly established. If our hypothesis that $\delta^{13} \mathrm{C}$ of the gorgonians can be linked to changes in the isotopic composition of atmospheric carbon dioxide, then the observed trend in ${ }^{13} \mathrm{C}$ may reflect a regional perturbation in the atmospheric carbon cycle. The early 1940s corresponds with a switch in the Pacific Decadal Oscillation from positive to negative values (Mantua et al. 1997), reinforcing a possible connection between climate and the gorgonian skeleton.

The $\delta^{15} \mathrm{~N}$ trends exhibited by the specimens are not the same. Specimen P26 shows an enrichment in ${ }^{15} \mathrm{~N}$, PAL shows a depletion of ${ }^{15} \mathrm{~N}$, and P88 has no significant change in $\delta^{15} \mathrm{~N}$. The location of specimen P26 off the Aleutian Islands in the Alaskan Stream suggests it was influenced by the oceanography of the central subarctic region. Specimen PAL and P88 were both collected from the Gulf of Alaska shelf: it is likely that specimen PAL was influenced by the Alaska Current and specimen P88 by the general coastal currents.

Specimen P26 was collected from within the Alaskan Stream, an area of the North Pacific Ocean that is characterized by high-nutrient, low chlorophyll, seasonally stable phytoplankton stocks and lower production than that predicted by available nitrogen (Booth 1988). 
Consequently, it is an open system with a continuous supply of nitrogen. The $\delta^{15} \mathrm{~N}$ values of the plankton from which a major portion of POM is generated are relatively low, which would explain the similarly low $\delta^{15} \mathrm{~N}$ values of this specimen. This may change, however, as the supply of nitrate decreases. The depth of the mixed layer in the North Pacific Ocean has been decreasing over the past $40 \mathrm{yr}$ from $130 \mathrm{~m}$ in the 1960s to $100 \mathrm{~m}$ in 2000 (Freeland et al. 1997); consequently, it is more difficult for nutrient-rich waters to reach surface waters. Nitrate depletion in the surface layers has been reported in the 1990s with winter nutrient levels in 1997-1998 being half of those reported for the 1970s (Whitney et al. 1999). Reduced nutrients in surface waters results in greater utilization of nitrogen supplied during seasonal upwelling events. This could explain the ${ }^{15} \mathrm{~N}$ enrichment observed in P26 between 1940 and 2003.

Alternatively, the ${ }^{15} \mathrm{~N}$ enrichment in P26 could be explained by a shift in the plankton composition of the food source to the specimen. $\delta^{15} \mathrm{~N}$ is enriched by approximately $3.4 \%$ with each step in the food web; for example, zooplankton are ${ }^{15} \mathrm{~N}$ enriched compared to phytoplankton. In the central subarctic region, summer zooplankton biomass doubled from the 1950s to the 1980s (Brodeur et al. 1996). An increase in zooplankton, relative to phytoplankton, could have resulted in an enrichment in ${ }^{15} \mathrm{~N}$ of the food available to specimen P26, thus also potentially explaining the skeletal enrichment.

Specimen PAL, collected from the Gulf of Alaska shelf, exhibited a ${ }^{15} \mathrm{~N}$ depletion trend over time. This suggests either that nitrate supply is increasing relative to biological demand or that the food web has been altered, favouring organisms lower in the food chain. In contrast to much of the Gulf of Alaska, the coastal domain has much higher primary productivity resulting in high phytoplankton and zooplankton standing stocks (Sambrotto \& Lorensen 1996). Seasonal summer upwelling supplies nutrient-rich waters to the shelf (Childers et al. 2005), supporting a seasonal phytoplankton bloom in which nitrogen is the limiting nutrient (i.e. a closed system). The surface layer on the continental shelf is influenced by freshwater discharge, which has a low nitrate concentration, due to the high elevations and the glacial nature of the major drainage systems where the discharges are derived (Weingartner et al. 2005). There is some evidence that freshwater discharge, as a result of increased temperature and precipitation, has increased in southern Alaska since the 1970s (Royer 2005). This should have resulted in lower concentrations of nitrate entering the coastal marine systems, therefore a decrease in supply relative to demand. Consequently, this cannot explain the ${ }^{15} \mathrm{~N}$ depletion observed in PAL.
The nitrogen isotope trend in specimen PAL reflects changes in the trophic structure in the northern Gulf of Alaska since it is not related to nitrate concentration dynamics. The trophic web along the continental margin of the North Pacific Ocean is largely controlled by bottom-up processes (Ware \& Thomson 2005). Therefore, the ${ }^{15} \mathrm{~N}$ depletion could suggest that a slight increase in the abundance of phytoplankton relative to zooplankton has occurred in the Gulf of Alaska coastal domain. This would result in a decrease in the $\delta^{15} \mathrm{~N}$ signature of the food source to the specimen, explaining the ${ }^{15} \mathrm{~N}$ depletion with time.

Specimen P88 exhibits no significant trend in its skeletal $\delta^{15} \mathrm{~N}$ composition with time. It is unclear if the absence of a trend is a consequence of the relatively small number of bands sampled or a reflection of stable oceanographic conditions.

Climate patterns in the northern North Pacific Ocean affect plankton dynamics and could also be responsible for long-term isotope trends. $\delta^{13} \mathrm{C}$ and $\delta^{15} \mathrm{~N}$ results from all specimens were compared to climate patterns in the North Pacific Ocean, i.e. to climate regime shifts, Pacific Decadal Oscillation, the Aleutian Low Pressure Index and El Nino; no correlation along the time series was observed. This may indicate that the locations from which the specimens were collected were more strongly influenced by local factors than larger-scale regional ones, or alternatively that insufficient subsamples were analysed to detect statistically significant correlations.

Acknowledgements. Research was funded by NSERC grants to M.R. Thanks to the fisheries survey staff at the Alaska Fisheries Science Center of NOAA Fisheries for providing the deep-sea coral specimens. The authors thank J. McKay and A. Adamowicz for help with analyses. C. Hillaire-Marcel and O. Sherwood made constructive suggestions for the manuscript, and K. Juniper provided research support.

\section{LITERATURE CITED}

Altabet MA, Deuser WG, Honjo S, Seinen C (1991) Season and depth-related changes in the source of sinking particles in the North Atlantic. Nature 354:136-139

Andrews AH, Cordes E, Heifitz J, Cailliet GM, Coale KH, Somerton D, Munk K, Mahoney M (2002) Age and growth of a deep sea, habitat-forming octocorallian (Primnoa sp.) from the Gulf of Alaska, with radiometric age validation. Hydrobiologia 471:101-111

Booth B (1988) Size classes and major taxonomic groups of phytoplankton at two locations in the subarctic Pacific Ocean in May and August, 1984. Mar Biol 97:275-286

Brodeur R, Frost B, Hare S, Francis R, Ingraham W, Jr (1996) Interannual variability in zooplankton biomass in the Gulf of Alaska, and covariation with California Current zooplankton biomass. CalCOFI Report 37:80-99

Childers AR, Whitledge TE, Stockwell DA (2005) Seasonal and interannual variability in the distribution of nutrients 
and chlorophyll $a$ across the Gulf of Alaska shelf: 1998-2000. Deep-Sea Res II 52:193-216

Coyle K, Pinchuk A (2005) Seasonal cross-shelf distribution of major zooplankton taxa on the northern Gulf of Alaska shelf relative to water mass properties, species depth preferences and vertical migration behaviour. Deep-Sea Res II 52:217-245

Druffel ERM, King LL, Belastock RA, Buesseler KO (1990) Growth rate of a deep-sea coral using ${ }^{210} \mathrm{~Pb}$ and other isotopes. Geochim Cosmochim Acta 54:1493-1499

Feely R, Sabine C, Lee K, Millero F and 8 others (2002) In situ calcium carbonate dissolution in the Pacific Ocean. Global Biogeochem Cycles 16:1144, doi:1110.1029/2002GB001866

Francey R, Allison C, Etheridge D, Trudinger C and 5 others (1999) A 1000-year high precision record of $\delta^{13} \mathrm{C}$ in atmospheric $\mathrm{CO}_{2}$. Tell Ser B Chem Phys Meteorol 51:170-193

Freeland HJ, Denman K, Wong CS, Whitney F, Jacques R (1997) Evidence of change in the winter mixed layer in the northeast Pacific Ocean. Deep-Sea Res 44:2117-2129

Gearing J, Gearing P, Rudnick D, Requejo A, Hutchins M (1984) Isotopic variability of organic carbon in a phytoplankton-based temperate estuary. Geochim Cosmochim Acta 48:1089-1098

Grasshoff M, Zibrowius H (1983) Kalkkrusten auf Achsen von Hornkorallen, rezent und fossil. Senckenb Marit 15:111-145

Gruber N, Keeling CD, Bacastow RB, Guenther PR and 5 others (1999) Spatiotemporal patterns of carbon-13 in the global surface oceans and the oceanic Suess effect. Global Biogeochem Cycles 13:307-335

Heifetz J (2002) Coral in Alaska: distribution abundance, and species associations. Hydrobiologia 471:19-28

Heikoop JM, Hickmott DD, Risk MJ, Shearer CK, Atudorei V (2002) Potential climate signals from the deep-sea gorgonian coral Primnoa resedaeformis. Hydrobiologia 471:117-124

Hofmann M, Wolf-Gladrow D, Takahashi T, Sutherland S, Six K, Maier-Reimer E (2000) Stable carbon isotope distribution of particulate organic matter in the ocean: a model study. Mar Chem 72:131-150

Laws E, Popp B, Cassar N, Tanimoto J (2002) ${ }^{13} \mathrm{C}$ discrimination patterns in oceanic phytoplankton: likely influence of $\mathrm{CO}_{2}$ concentrating mechanisms, and implications for palaeoreconstructions. Funct Plant Biol 29:323-333

Mantua NJ, Hare SR, Zhang Y, Wallace JM, Francis RC (1997) A Pacific interdecadal climate oscillation with impacts on salmon production. Bull Am Meteorol Soc 78:1069-1079

Needoba JA, Waser NA, Harrison PJ, Calvert SE (2003) Nitrogen isotope fractionation in 12 species of marine phytoplankton during growth on nitrate. Mar Ecol Prog Ser 255: 81-91

Orejas C, Gili JM, Arntz W (2003) The role of the small plankton communities in the diet of two Antarctic octocorals (Primnoisis antarctica and Primnoella sp.). Mar Ecol Prog Ser 250:105-116

Quay PC, Tilbrook B, Wong CS (1992) Oceanic uptake of fossil fuel $\mathrm{CO}_{2}$ : carbon-13 evidence. Science 256:74-79

Risk MJ, Heikoop JM, Snow MG, Beukens R (2002) Lifespans and growth patterns oftwo deep-sea corals: Primnoa resedaeformis and Desmophyllum cristigalli. Hydrobiologia 471:125-131

Royer TC (1975) Seasonal variations of water in the northern Gulf of Alaska. Deep-Sea Res 22:403-416

Editorial responsibility: Otto Kinne (Editor-in-Chief), Oldendorf/Luhe, Germany
Royer TC (1981) Baroclinic transport in the Gulf of Alaska. II. A fresh water driven Coastal Current. J Mar Res 39:251-266

Royer TC (2005) Hydrographic responses at a coastal site in the northern Gulf of Alaska to seasonal and interannual forcing. Deep-Sea Res II 52:267-288

Sambrotto R, Lorensen C (1996) Phytoplankton and primary production. In: Hood D, Zimmerman S (eds) The Gulf of Alaska: physical environment and biological resources. Minerals Management Services, Springfield, VA, p 249-282

Sarkar N, Royer T, Grosch C (2005) Hydrographic and mixed layer depth variability on the shelf in the northern Gulf of Alaska, 1974-1998. Cont Shelf Res 25:2147-2162

Sherwood OA (2002) The deep-sea gorgonian coral Primnoa resedaeformis as an oceanographic monitor. MS thesis, McMaster University, Hamilton, Canada

Sherwood OA, Scott DB, Risk MJ, Guilderson TP (2005a) Radiocarbon evidence for annual growth rings in the deep-sea octocoral Primnoa resedaeformis. Mar Ecol Prog Ser 301:129-134

Sherwood OA, Heikoop JM, Scott DB, Risk MJ, Guilderson TP, McKinney RA (2005b) Stable isotoptic composition of deep-sea gorgonian corals Primnoa spp.: a new archive of surface processes. Mar Ecol Prog Ser 301:135-148

Stabeno P, Bond N, Hermann A, Kachel N, Mordy C, Overland J (2004) Meteorology and oceanography of the Northern Gulf of Alaska. Cont Shelf Res 24:859-897

Steiner R (1998) Deforestation in Alaska's coastal rainforest: causes and solutions. North American Workshop on the Underlying Causes of Deforestation and Forest Degradation, Winnipeg

Tanaka T, Watanabe Y, Watanabe S, Noriki S, Tsurushima N, Nojiri Y (2003) Oceanic Suess effect of $\delta^{13} \mathrm{C}$ in subpolar region: the North Pacific. Geophys Res Lett 30:2159, doi: 10.1029/2003GL018503

Tunnicliffe V (2000) A fine-scale record of 130 years of organic carbon deposition in an anoxic fjord, Saanich Inlet, British Columbia. Limnol Oceanogr 45:1380-1387

Ware D, Thomson R (2005) Bottom-up ecosystem trophic dynamics determine fish production in the northeast Pacific. Science 308:1280-1284

Waser NAD, Harrison PJ, Head EJH, Nielsen B, Lutz VA, Calvert SE (2000) Geographic variations in the nitrogen isotope composition of surface particulate nitrogen and new production across the North Atlantic Ocean. DeepSea Res I 47:1207-1226

Weingartner TJ, Danielson SL, Royer TC (2005) Freshwater variability and predictability in the Alaska coastal current. Deep-Sea Res II 52:169-191

Whitney F, Mackas D, Welch D, Robert M (1999) Impact of the 1990s El Niños on nutrient supply and productivity of Gulf of Alaska waters. In: PICES (ed) Proceedings of the 1998 Science Board Symposium on the Impacts of the 1997/98 El Niño Event on the North Pacific Ocean and Its Marginal Seas, Report 10. North Pacific Marine Science Organization (PICES), Sidney

Wu J, Calvert SE, Wong CS (1997) Nitrogen isotope variations in the subarctic Pacific: relationships to nitrate utilization and trophic structure. Deep-Sea Res 44:287-314

Xiong Q, Royer TC (1984) Coastal temperature and salinity in the northern Gulf of Alaska. J Geophys Res 89: 8061-8068

Submitted: July 13, 2005; Accepted: July 14, 2006

Proofs received from author(s): March 23, 2007 